\title{
Developing an understanding of Post Traumatic Growth: Implications and application for research and intervention
}

\author{
Monica Sanki · Sean A. O'Connor
}

\begin{abstract}
Post Traumatic Growth (PTG) has been shown to occur following a range of traumatic experiences and interest in the construct has increased exponentially in recent years. Through a systematic literature review, this paper explores PTG's philosophical and theoretical foundations, reviews some of the controversies surrounding its definition, measurement, and characterisation, and seeks to elicit some common factors supporting its development. Of particular interest are the potential applications and implications of these factors in broader contexts. PTG's theoretical links to Expert Companionship, Organismic Valuing Theory, and Self Determination Theory, and the role of narrative in rebuilding personality, all indicate alignment with the philosophy and practice of positive psychology. While the study of this area is still evolving, this paper suggests there are many potential applications and implications of PTG.
\end{abstract}

Keywords: post traumatic growth; post traumatic stress; positive psychology; coaching; growth; personal development; intervention

\section{Introduction}

The concept of growth following trauma is a commonly held concept within the populous psyche (Gorman, 2019; Hooton, 2018) embedded historically throughout shared mythology, religion and cultural literature (Joseph, 2011; Tedeschi, Shakespeare-Finch, Taku, \& Calhoun, 2018). Philosophically, existentialism's focus on individualist meaning making shape current understanding of PTG. Growth and recovery are seemingly intertwined in our societal narrative of human evolution and yet there has been minimal investigation into factors enabling recovery from trauma with a view to growth and wellbeing.

Historically, psychology's focus on the identification and codification of pathology has done little to improve prevention approaches (Seligman, 2000; Sheldon \& King, 2001). More recently, positive psychology's focus on 'strength and virtue' (Seligman, 2000, p. 7), has shown strengths such as courage, optimism, work ethic, hope, honesty and capacity for flow can act as buffers against mental illness, supporting wellbeing (Seligman, 2000). Positive psychological research places emphasis on personal autonomy (Peterson, Maier, \& Seligman, 1993), evident in PTG.

PTG was first coined by Tedeschi and Calhoun (1995), with early reports of PTG emerging in the late 1980's and 1990's. Through a systematic literature review, this paper explores PTG's philosophical and theoretical foundations, reviews some of the controversies surrounding its definition, measurement, and characterisation, and seeks to elicit some common factors

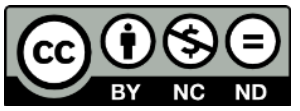

Copyright belongs to the author(s) www.internationaljournalofwellbeing.org 
supporting its development. A discussion then follows proposing future research and implications for intervention.

\subsection{Post traumatic growth - Philosophical and theoretical foundations}

The philosophical foundations of PTG are anchored in the proposition that positive human health requires the confrontation of negative life experiences (Ryff \& Singer, 1998). This strikes directly at the paradoxical heart of the construct and represents a philosophical shift away from pathology to salutogenisis (Tedeschi et al., 2018). Early interest in PTG led to multiple attempts at definition. One theoretical concept central to PTG is that of shattered assumptions (JanoffBulman, 1992), which acknowledges that an event can challenge the adaptive resources and world view of an individual (Janoff-Bulman, 1992). Trauma, being highly subjective, means coping will be determined by a person's attachment of meaning to the traumatic event (Frankl, 1985).

While there is no universally accepted definition of PTG (Joseph, 2012; Peterson, Park, Pole, D'Andrea, \& Seligman, 2008), Tedeschi and Calhoun's (1995) characterisation of PTG as a positive transformation following struggle with trauma or highly challenging circumstances, is widely relied upon (Tedeschi \& Calhoun, 1995a). This definition focuses broadly on highly challenging life circumstances, separate from life stressors and hassles (Tedeschi et al., 2018), moving away from definitions of Post Traumatic Stress Disorder (PTSD) requiring life threatening experiences (5th edition; DSM-5). Trauma is therefore defined as any scenario which is transformative in nature, challenging a person's sense of self, sense making and assumptive worldview (Janoff-Bulman, 1992; Joseph \& Linley, 2004; Tedeschi et al., 2018).

Psychological change comes from the process of dealing with trauma, rather than its survival (Tedeschi \& Calhoun, 1995b). This points to the process of some kind of reflective engagement with a traumatic experience that may be significant in supporting a positive developmental shift. Importantly, the key is not a return to the pre-trauma state, but experiencing personally significant growth (Tedeschi \& Calhoun, 2004). This has been evidenced through enhanced relationships; a deeper and more accurate sense of self; and perspective shift on life, meaning and personal values (Joseph \& Linley, 2004; Tedeschi \& Calhoun, 1995a).

Linley and Joseph (2005) extend this view on PTG, taking an affective-cognitive organismic valuing approach. Leveraging from a person-centred approach (Rogers, 1951) and Self Determination Theory (Ryan \& Deci, 2000), organismic valuing proposes humans are driven towards growth and innately understand the requirements supportive of wellbeing (Joseph \& Linley, 2005). In contrast, Tedeschi and Calhoun's (1995) model, characterised by persistent cognitive processing, is argued to be aligned to the hedonic tradition of subjective wellbeing, and seeking out feelings of wellbeing (Linley \& Joseph, 2005). Linley and Joseph's (2005) thinking centres on eudaimonia and accounts for the motivations for change and the dynamic nature of the growth process (Joseph \& Linley, 2005). It is thought that confronting trauma and selfrebuilding results in a more fully functioning and self-accepting individual, seeking to live a more purposeful and authentic life (Joseph \& Linley, 2005).

Importantly, both theories recommend an expert companion to guide the trauma sufferer on their journey of cognitive restructuring and search for meaning (Joseph, 2011; Tedeschi et al., 2018), suggesting that guided reflection and observation are best placed to support development of self and encourage positive eudemonic and hedonic wellbeing. With a focus on the deeper transformation at the psychological wellbeing level, supporting the sufferer to listen and observe their own psychological experience is central to developing autonomy through recovery (Joseph \& Linley, 2005). While distinguishing importantly that those still overwhelmed by distress will 
not be ready for this stage of growth and require clinical support, the expert companion could be, but does not necessarily need to be, a traditional therapist, but someone who can provide a client centred approach to facilitate growth, including social workers, psychotherapists, coaches or pastoral counsellors (Joseph, 2011; Tedeschi et al., 2018).

To support expert companionship, Joseph (2011) developed the THRIVE model designed to facilitate PTG. This six stage model includes the steps of taking stock, harvesting hope, reauthoring, identifying then valuing change, finishing with expressing change in action (Joseph, 2011), with this final stage triggering much theoretical debate. Hobfoll et al.'s (2007) study identified the role of action in both evidencing and empowering PTG, stating that PTG can only truly be evidenced through action, directly challenging Tedeschi and Calhoun's (1995) cognitive model (Hobfoll et al., 2007). Hobfoll et al., (2007) lean strongly on the writing of Frankl (1985) with his focus on 'right action and right conduct' supporting his search for meaning and discovery of meaning in action (Frankl, 1985).

Interestingly, PTG has received exponential focus in recent years. A PsychInfo database search on 29 April 2019 using the keyword 'Posttraumatic Growth' revealed 1297 papers of which 819 have been published since 2014. Intrigued by our understanding of the philosophical and theoretical foundations of PTG and the growing interest in the construct within the research community, we reviewed and analysed the existing literature to gain a deeper understanding of PTG's current theoretical developments, factors and applications.

\section{Method}

\subsection{Literature review}

The PRISMA statement (Moher, Liberati, Tetzlaff, \& Altman, 2009) was consulted to guide both the data search and resource selection process of this literature review. Initially a data search was conducted on the following databases using the term "Posttraumatic Growth"; Psych Info, Business Source Ultimate, Sydney University Library database and Google Scholar. Initially, the search focussed on building a resource base to provide an overview of current conceptualisation of the construct and key theorists. Once this was established, searches focussed on identifying key meta-studies that furthered the development of the construct including factors and debates regarding theoretical approaches. From these meta-studies, individual case studies were identified that illustrated specific concepts or assisted in the development of the construct factors. Finally contact was made with a practitioner active in the field of trauma in order to access unpublished data and perspectives.

\subsection{Categorisation and Inclusion Criteria}

In reviewing the studies and articles, the authors identified and organised the data into five key categories - key theorists; factors; measures and definition; issues and controversy; and implications for intervention. Some of these were then broken into subcategories, for instance, the factor category, in particular, consisted of a number of sub-categories including, coping, distress/growth, cognition/action, optimism and social support, cultural factors, resilience, rumination and impact of time amongst others. As the detailed review progressed, additional backward and forward searches were also undertaken to further illicit relevant materials. These materials were subjected to the same review process as detailed above.

\subsection{Studies Included}

As a result of the process adopted in the data collection and classification stage, 132 out of the 
149 resources reviewed in detail, were included in the final literature review. This meant that the collection and collation of data in the previous two stages sufficiently identified material relevant to providing both an overview of the construct and the development of potential implications for intervention. Table 1 provides an overview of the development of PTG theory via primary theorists and the key meta-studies as reviewed in this paper.

Table 1

Summarised PTG Theory Research Up To 2018.

\begin{tabular}{ll}
\hline Author & $\begin{array}{l}\text { Key Contributions to Development of PTG } \\
\text { construct }\end{array}$ \\
\hline Janoff-Bulmann 1992 & $\begin{array}{l}\text { Defining assumption shattering events and } \\
\text { their impacts }\end{array}$ \\
\hline Tedeschi \& Calhoun 1995, 1996 & $\begin{array}{l}\text { Original coining of the term posttraumatic } \\
\text { growth }\end{array}$ \\
\hline Linley \& Joseph 2004, 2005 & $\begin{array}{l}\text { Review of the PTG literature to date and } \\
\text { development of an affective-cognitive } \\
\text { organismic valuing approach to PTG }\end{array}$ \\
\hline Maerkle \& Zoellner 2004 & $\begin{array}{l}\text { Janus Face Model of PTG - identification of } \\
\text { the potentially illusory aspects of PTG. Meta } \\
\text { study }\end{array}$ \\
\hline Hobfoll et al 2007 & $\begin{array}{l}\text { PTG as illusory, needs change expressed as } \\
\text { action, not only a cognitive process }\end{array}$ \\
\hline Prati \& Pietrantoni 2009 & $\begin{array}{l}\text { Optimism, social support and coping } \\
\text { strategies - meta study in PTG factors }\end{array}$ \\
\hline Joseph 2011 book & $\begin{array}{l}\text { Deeper articulation of the affective-cognitive } \\
\text { organismic valuing approach and practical } \\
\text { applications including THRIVE Model }\end{array}$ \\
\hline Jayawickreme \& Blackie 2014 & $\begin{array}{l}\text { Meta study - PTG as positive personality } \\
\text { change review of evidence and } \\
\text { controversies }\end{array}$ \\
\hline & $\begin{array}{l}\text { Two versions, originally published in 2004, } \\
\text { then updated in 2018, comprehensive } \\
\text { overview of the construct, measures, factors } \\
\text { and variables }\end{array}$ \\
\hline
\end{tabular}

\section{Results}

Of the materials retrieved in the initial searches, the majority are case studies documenting PTG of survivors of natural disaster, serious illness and violent crime. The remainder are devoted to various theorists seeking to explore and measure the construct and related meta studies and literature reviews. Consistent with the evolving nature of PTG's definition, the initial results revealed that the study and articulation of the exact nature, measures and elements of PTG is inconsistent (Hobfoll et al., 2007). What does emerge though, are a set of common factors supporting PTG. While all of the factors identified in the research do not need to be in place for 
PTG to evolve, they do indicate there are a group of essential key factors.

\subsection{Factors supporting PTG}

The existence of PTG does not mean that trauma is a precursor to personal growth. Trauma is highly stressful, with each person responding differently, based on a multitude of variables (Tedeschi \& Calhoun, 2004). Each of the below are shown by research to support PTG, however individuals vary in their response to trauma, and so not all factors discussed are necessarily required in order to support PTG.

\subsubsection{Relationship between growth and distress}

Variables such as the intensity, severity and duration of the trauma will impact the stress response. Sadness and depression are common responses, as are guilt, anger and irritability (Tedeschi \& Calhoun, 2004). These are usually accompanied by the commencement of distressing and dysfunctional thought patterns, including intrusive rumination (Tedeschi \& Calhoun, 2004). Our natural inclination is to try to alleviate such pain and distress. However the evidence reveals that in order to experience PTG, a level of distress is required (Frazier, Conlon, \& Glaser, 2001; Hobfoll et al., 2007). Across multiple breast cancer studies levels of PTG were higher across those who were more severely impacted by the disease and showed higher levels of distress (Sumalla et al., 2009). Similar results were found in survivors of the Dresden bombings, where proximity related to higher levels of distress, and higher levels of growth (Maercker \& Herrle, 2003).

It is important to distinguish between the alleviation of distress, shown not to promote growth, and the experience of growth found to alleviate distress (Frazier et al., 2001; Joseph, 2011). This speaks to the core paradoxical nature of PTG, requiring both the experience and exploration of distress for developmental growth. While highly challenging, this process is seen as essential for growth (Joseph, 2011; Tedeschi et al., 2018). The relationship between growth and distress are coexistent (Tedeschi et al., 2018) and do not sit at opposite ends of a continuum (Joseph, 2011). While current pharmacological practices of treating post traumatic stress (PTS) and PTSD focus on symptomatic alleviation for immediate short term mental recovery, more is needed to support potential longer term positive developmental growth that may arise from facing challenging experiences (Joseph, 2011). Indeed the experience of distress can exist in conjunction with feelings of wellbeing following PTG (Joseph, 2011).

\subsubsection{Relationship between PTSD, PTS and PTG}

Given the links between growth and distress, what then of the relationship between PTG, PTS and PTSD? To view PTSD as negative and PTG as positive along a single continuum of possible outcomes oversimplifies the constructs and fails to address the complex human response to trauma (Tedeschi et al., 2018; Westphal \& Bonanno, 2007).

Again, there are inconsistencies across studies. A stronger curvilinear relationship has been found where there is a relationship between levels of distress and PTG (Helgeson et al., 2006). Two studies in particular revealed a curvilinear relationship between distress level and growth, one a breast cancer study where those with stages 1 and IV reported lower levels of benefit finding than those with stage II (Lechner et al., 2003), and Vietnam veterans who experienced the greater levels of benefit finding were those exposed to a moderate level of trauma distress, as opposed to low or high trauma exposure (Fontana \& Rosenheck, 1998). These results were supported by Shakespeare-Finch and Lurie-Beck's (2014) meta study which also found the curvilinear relationship was moderated by age and trauma type (Shakespeare-Finch \& Lurie- 
Beck, 2014). For instance a more linear relationship was found amongst children (Jin, Xu, \& Liu, 2014; Kilmer et al., 2009), and stronger relationships found in natural disasters as opposed to following sexual assault (Shakespeare-Finch \& Lurie-Beck, 2014).

The curvilinear relationship between the symptoms of PTSD and PTG suggests that there is a point beyond which the symptoms of PTSD become overwhelming and hamper the cognitive process of meaning making and growth (Joseph, 2011). This curvilinear relationship also supports the basis that there cannot be PTG without some level of PTS (Joseph, 2011; Shakespeare-Finch \& Lurie-Beck, 2014).

It is therefore important to distinguish that while PTSD, PTS and PTG are related as arising out of the same traumatic event, they are different processes. While working with the distress, guilt and intrusive rumination associated with PTSD, one can also start to work on the process of deliberate rumination and transformative change of integrating a new assumptive worldview (Tedeschi et al., 2018). Symptoms of PTSD, including post traumatic health deterioration, can coexist with the process and outcomes of PTG (Maercker \& Herrle, 2003).

\subsubsection{Relationship between Rumination, Assimilation and Accommodation}

Rumination, a repetitive focus on distress, its causes and consequences (Nolen-Hoeksema, Wisco, \& Lyubomirsky, 2008) has been traditionally thought of as a maladaptive response to stressful and emotional events, negatively impacting physical and mental wellbeing (Garcia, Duque, \& Cova, 2017; Hughes, Alloy, \& Cogswell, 2008). Recent studies have indicated that rumination may be multidimensional and highlighted the importance of distinguishing between its different forms, with each having different characteristics and impacts (Garcia et al., 2017; Tanner, Voon, Hasking, \& Martin, 2013).

Brooding and reflection are two clear subtypes of rumination (Treynor, Gonzalez, \& NolenHoeksema, 2003), with brooding characterised as a passive comparative exercise with maladaptive outcomes (Treynor et al., 2003) and attentional bias to emotional and negative data (Garcia et al., 2017), and reflection an adaptive cognitive problem solving process (Treynor et al., 2003) with no negative attentional bias (Garcia et al., 2017).

Calhoun and Tedeschi (2006) further separate ruminative thoughts into automatic intrusive thoughts and deliberate rumination on an event's meaning (Calhoun \& Tedeschi, 2006). Automatic intrusive thoughts have been associated with PTSD, and deliberate rumination to PTG (Garcia et al., 2017). In fact, Garcia et al.'s (2017) study demonstrated that deliberate reflective rumination is a predictor of PTG (Garcia et al., 2017), building on prior clinical application of this proposition (Waters \& Strauss, 2016).

These factors are linked to the relationship between growth and distress. Trauma survivors will experience a phase of intrusive rumination, where they are not in control of the thoughts and images that come back to them. This is a highly distressing phase that can last for weeks or months post trauma (Joseph, 2011), however is essential as it represents the brain's natural way of dealing with trauma, trying to 'file' away or process memories and experiences (Joseph, 2011; Van der Kolk, 2015).

This distressing phase represents the struggle between the processes of accommodation and assimilation (Joseph, 2011). Trauma brings a complete breakdown in an individual's assumptive worldview, and with it the choice to continue to function as though those assumptions remain intact (assimilation) or acknowledging their breakdown and re-building new ones (accommodation) (Joseph, 2011). It is proposed that PTG is the result of accommodation, of working with the experience of trauma to build something new (Joseph, 2011). Working with rumination as 
reflection, as opposed to brooding, supports meaning making, building new ways of dealing with trauma and relating to the world (Joseph, 2011).

\subsubsection{Social support and disclosure}

Central to the process of accommodation is the role of self-disclosure to others about the trauma. The practice of disclosing one's intrusive thoughts and feelings have been shown to support the shift towards deliberate and reflective rumination (Tedeschi et al., 2018).

Self-disclosure can take many forms, including written stories, music or even dance or verbal recounts (Tedeschi et al., 2018). The form of disclosure however is not as important as the role of the listener or recipient. The relationship of this factor to growth lies in the quality of social support. It is vital that the trauma sufferer feels heard and supported in order to truly benefit from the process of disclosure (Tedeschi et al., 2018). Family and friends are often not ideal, given the challenging nature and subject matter of the disclosure, where they will often react to alleviate discomfort. Professional help that can truly accept and listen to the challenging experiences of the sufferer, provide support while balancing discomfort, engage in deliberate rumination and rebuild assumptive worldviews is better placed to support the process of developmental growth (Joseph, 2011).

\subsubsection{Coping strategies}

Interestingly, there is evidence that both approach based coping (Helgeson et al., 2006; Prati \& Pietrantoni, 2009) as well as avoidant based coping support higher levels of PTG (Helgeson et al., 2006). Trauma sufferers need brief and limited periods of avoidant coping such as denial, to allow distress relief, prior to the more overwhelming and confronting process of approach coping (Kunz et al., 2018). A flexible approach to coping styles is required, providing important evidence that while approach oriented coping has been shown as most effective in supporting PTG in trauma populations (Helgeson et al., 2006; Prati \& Pietrantoni, 2009), it's effectiveness can be enhanced by specific and limited use of avoidant coping, especially effective in the early stages post trauma (Kunz et al., 2018).

\subsubsection{Impact of Time}

Both Tedeschi and Calhoun (1995) and Joseph and Linley (2005) theorise the transformative schematic changes inherent in the PTG process require time to unfold and evolve. Empirically, the relationship between time and PTG is complex with the relative lack of longitudinal studies tracking PTG from time of trauma over many years. The Dresden bombing study revealed PTG effects some 52 years post the event, however there is no study showing how growth manifested and evolved over this period (Maercker \& Herrle, 2003).

Additionally, short term studies may not account for the individual trajectories of growth and fail to detect PTG that is yet to appear. There seems to be a relationship between distress level and benefit finding (Helgeson et al., 2006), however those who did not score highly may merely take longer for PTG to manifest. Indeed, this meta study showed those exposed to higher levels of distress revealed lower levels of benefit finding. Other studies reveal between four to six different trajectories, indicating growth both increasing and then tapering off over time (Tedeschi et al., 2018).

\subsubsection{Measures and Evidence}

While a full review of measurement approaches is beyond the scope and purpose of this paper, 
it is important to identify themes that emerge relating to research and potential intervention approaches. A range of self-report scales have been developed since the 1990's. These include the Posttraumatic Growth Inventory (PTGI; Tedeschi \& Calhoun, 1995, 1996), The Stress-Related Growth Scale (SRGS; Park et al., 1996), The Revised Stress-Related Growth Scale (RSRGS; Armeli et al., 2001), The Changes in Outlook Questionnaire (CiOQ; Joseph et al., 1993), and the Thriving Scale (TS; Abraido-Lanza et al., 1998). There is also the Perceived Benefit Scales (PBS; McMillen \& Fisher, 1998), and The Psychological Well-Being Posttraumatic Changes Questionnaire (PWB-PTCQ; Joseph, et al., 2012). These measures vary greatly in number of items and factors as well as defined areas of focus. The SRGS and the RSRGS focus on factors such as resources and coping while the PTGI and the CiOQ focus on perspective shifts on experience. Others focus more specifically on perception of change or benefit such as the PBS, while finally the PWB-PTCQ focuses specifically on aspect of wellbeing post trauma.

There is wide variation in the approach to measurement that significantly clouds the definition of PTG as a construct, severely limiting focused approaches to research and intervention. Tedeschi et al (2018) argue that both the terminology and measurement of stress related growth, change in outlook, thriving and perceived benefits need to be distinguished from PTG (Tedeschi et al., 2018). While these terms share growth following challenge or stress in common, none effectively address the nature of trauma as a challenge to core beliefs and the transformative journey of post trauma growth (Tedeschi et al., 2018). It is therefore argued that using these scales are not relevant for the measurement of PTG and risk confusing constructs (Tedeschi et al., 2018).

The PTGI (Tedeschi \& Calhoun, 1996) is the most commonly used (Joseph \& Linley, 2004), widely validated (Andysz, Najder, Merecz-Kot, \& Wojcik, 2015; Palmer, Graca, \& Occhietti, 2012; Yoshida et al., 2016), cross-culturally and across numerous languages (la Cour, Nielsen, Andersen, \& Madsen, 2016; Lamela, Figueiredo, Bastos, \& Martins, 2014; Mack et al., 2015). Additionally, it is the only measure that has validly provided data to allow comparison between experiences (Middleton, 2016) and has spawned a number of variants (Cann et al., 2010; Hooper, Marotta, \& Depuy, 2009; Horswill, Desgagne, Parkerson, Carleton, \& Asmundson, 2016; Morris, Wilson, \& Chambers, 2013). Despite the PTGI's apparent validity, widespread use and extension, there is controversy and lack of agreement as to its effectiveness (Horswill et al., 2016).

Finally, inconsistencies in interpreting results show a divergent range of PTG prevalence, with one meta-study illustrating a range from 3\% for bereavement to $98 \%$ for breast cancer survivors (Linley \& Joseph, 2004). While some adopt a narrow approach requiring positive report on all factors, Tedeschi et al., (2018) argue for a liberal approach, taking even one positive report on one of their PTGI factors, if significant enough in that person's life, as sufficient evidence of PTG (Tedeschi et al., 2018). The inconsistency of approach regarding the measurement and prevalence of PTG underlines a key issue and controversy regarding the factual reality of PTG as a construct.

\section{Discussion}

The ongoing inconsistencies regarding the study and reduction of PTG to agreed factors belies the perspective that they are all, in their contexts, correct.

PTG is often confused with recovery, bringing connotations of the eventual removal of struggle and distress. The inconsistencies and debates plaguing PTG mean that a human centred approach is crucial for building a sound working theory of PTG. Seeking a singular definitive approach in this complex human reaction to trauma is short sighted. 


\subsection{Is PTG real or illusory - Issues and controversy}

The largely retrospective self-reported perception-based approach to measurement of PTG belies the question as to whether actual growth is assessed (Frazier et al., 2009). While there is no doubt that self-reports of PTG can be genuine, there is a clear possibility of an illusory component (Jayawickreme \& Blackie, 2014; Nolen-Hoeksema \& Davis, 2004).

Ascertaining self-reported PTG as actual or illusory growth is key to PTG research (Boals \& Schuler, 2018). Maintaining positive illusions has been shown to be important for psychological health, especially following traumatic circumstances (Taylor, Kemeny, Reed, Bower, \& Gruenewald, 2000). Retrospective PTG self-reports could be easily attributed to coping and efforts to maintain a positive outlook during distress (Taylor et al., 2000).

Those still distressed post trauma are assumed to report illusory PTG, often linked to selfprotective behaviours such as past derogations of the self (McFarland \& Alvaro, 2000; Westphal \& Bonanno, 2007), which is suggested help maintain positive illusions (McFarland \& Alvaro, 2000). Alternately, those no longer distressed post trauma are assumed to report actual growth, reflecting positive adaptation (Boals \& Schuler, 2018).

Often, particularly in the experience of cancer, there is pressure to develop a positive attitude as a key to healing. This in turn can result in false expectations and increased pressure to remain positive, survive and also to thrive (Sumalla, Ochoa, \& Blanco, 2009), increasing the distinguishability between real and illusory PTG further.

Linley and Joseph (2004) further identify both behavioural and physiological indicators that can influence PTG (Linley \& Joseph, 2004). Citing Bloom's (1998) work on the social transformation of trauma, they highlight the importance of social and political connection and attachment as antecedents to PTG (Bloom, 1998), and the work of Epel et al. (1998), who linked the incidence and speed of PTG to adaptive hormonal stress responses from repeated stress exposure (Epel, McEwen, \& Ickovics, 1998).

Evidence of cultural differences in trauma and PTG (Splevins, Cohen, Bowley, \& Joseph, 2010; Zheng \& Gray, 2015) additionally complicate current understandings. Studies of US trauma survivors show higher levels of PTG than those in Australia (Morris, Shakespeare-Finch, Rieck, \& Newbery, 2005), Japan (Taku \& Cann, 2014) and Spain (Steger, Frazier, \& Zacchanini, 2008). This difference is attributed to social pressure in the US to seek positives to challenging events (Zoellner, Rabe, Karl, \& Maercker, 2008). Collective cultures such as Japan and in the Southern Americas also show definite patterns of collective growth (Tedeschi et al., 2018), raising again the question of illusory processes within PTG.

Exploring illusory PTG in more detail, Helgeson et al.'s (2006) study highlights the difficulty in distinguishing this issue, and theorises that researchers may not be studying the same construct (Helgeson, Reynolds, \& Tomich, 2006). Growth may be the result of a number of processes, whether actual change, coping, or cognitive manipulations which operate to relieve distress (Helgeson et al., 2006). Importantly, Kunz et al.'s (2018) study showed that PTG could be seen as the result of flexible coping styles consisting of both avoidant and approach coping strategies (Kunz, Joseph, Geyh, \& Peter, 2018). Using avoidant coping, such as denial, sparingly provides psychological safety, allowing individual distress reduction, prior to embarking on the confronting approach coping strategies to build PTG (Kunz et al., 2018).

These studies align with Tedeschi et al.'s (2018) proposition that distinguishes between the processes and the outcomes of PTG. Elements that form potential illusory aspects of PTG, are in fact part of the process of PTG. Immediately post trauma, people are still working within their traumatic exposure, characterised by struggle. Illusory or self-protective factors work to assist through this distressing stage, but are essentially dominated by perceptions of PTG, and so any 
notions of growth are not sustainable (Tedeschi et al., 2018). However, once the process of PTG has run its full course, PTG as an outcome produces a different and more sustainable result (Tedeschi et al., 2018).

\subsection{The challenge of studying PTG}

\subsubsection{Longitudinal studies}

Trauma research is beset with logistic and ethical issues, with opportunities for pre/post trauma testing severely limited (Norris, 1996). It is argued that only through longitudinal research that the predictors and process of PTG can be reliably understood allowing better principles to be developed and therefore scientifically valid conclusions to be drawn (Joseph \& Linley, 2004). Limited existing longitudinal studies are often limited to specific trauma, preventing their broader application (Kunz et al., 2018). Furthermore, PTG has been shown to manifest in multiple phases over time and shorter term longitudinal studies may not support a clear understanding of the evolution of PTG (Tedeschi et al., 2018).

\subsubsection{Quantitative or Qualitative?}

The intensely personal journey of PTG raises the question whether a single method quantitative analysis is valid (Tedeschi et al., 2018). The difference between Australia's low mean PTGI scale (Morris et al., 2005) compared to similar Unites States studies (Tedeschi \& Calhoun, 1996) simply provide a generalised understanding of PTG incidence across two populations. Qualitative analysis is required to understand this data in more specific ways in order to develop insight into intervention and support approaches.

Additionally, qualitative study has brought the richness and diversity of cultural differences in PTG to the fore (Weiss \& Berger, 2010). Different cultures address and tackle the growth journey in unique ways, distinguishing universal and culture specific approaches to PTG (Weiss \& Berger, 2010). For example, collective approaches focussing on duty to family, community and country have supported Burmese refugee adjustment in Australia (Shakespeare-Finch, Schweitzer, King, \& Brough, 2014) and in African populations surviving and tolerating hardship were viewed as core to their cultural heritage rather than as signs of growth (Copping \& Shakespeare-Finch, 2013). These studies illustrate the important role qualitative data can play in understanding the nuances of PTG.

\subsection{Post traumatic growth - Implications for intervention and support}

With trauma the traditional domain of clinical interventions, Spence and Joseph (2107) rightly argue for caution, however theoretical and empirical evidence of PTG raise a number of potential opportunities for intervention and support.

\subsubsection{Expert companions}

A common theme across theorists is the importance of an expert companion to guide and facilitate the PTG journey (Calhoun \& Tedeschi, 2013; Joseph, 2011). As an expert, the emphasis is on facilitation and enablement, not the expert creation of growth, and as a companion the priority is to simply be present and non-judgmental (Calhoun \& Tedeschi, 2013; Middleton, 2016). Rogers' (1951) elements of empathy, genuineness and unconditional positive regard enable the expert companion to listen for underlying meanings, all required conditions to support effective therapeutic change (Calhoun \& Tedeschi, 2013).

The power of the expert companion in therapeutic environments should not be 
underestimated (Norcross \& Wampold, 2011). While there is evidence to support the power of talking therapies to build lasting change (Jirek, 2017; Rossouw, 2013), this is centred on the 'person' of the expert companion to engage and provide the right environment of trust and empathy to lay the foundations for change (Rossouw, 2013).

With a focus on seeking to understand and appreciate the experience of the client, the expert companion creates the necessary environment of safety for the exploration of the challenging emotional and cognitive exploration of trauma, shown to support the development of PTG. Understanding that trauma has many pathways, the expert companion does not seek to direct the client towards an outcome, but rather supports deliberative rumination and re-appraisal of assumptions to develop an individual pathway for PTG (Tedeschi \& Blevins, 2017).

\subsubsection{Action}

Action in the context of PTG is key to delineating between aspects of illusory PTG and the process and outcome of PTG. While Hobfoll et al., (2007) rely on action as evidence of PTG, Tedeschi et al., (2018) see actions as the outcome of the PTG process. On both interpretations, there is alignment with the action methodology and outcome focus of coaching based approaches, taking change beyond the realm of cognitive shift, into evidence of positive action and behaviours that embed change sustainably.

\subsubsection{Narrative and reauthoring}

Narrative and rebuilding of life story and its importance in personal growth is not new (Drake, 2015), and while not the only factor supporting PTG, it is a core component to rebuilding shattered assumptions. Working with narrative opens up the possibility of different interpretations of events and experiences (Calhoun \& Tedeschi, 2013), allowing the development of a life narrative to support the accommodation of trauma, facilitating growth (Jirek, 2017; Joseph \& Linley, 2005).

\subsubsection{Working with suffering as a fertiliser for growth}

Adult development is not linear and demands a person-centred approach to individually challenge. Discontinuous change is also linked to PTG as is the cumulation of extreme emotion and challenge as the precursors of change (Hayes, Laurenceau, Feldman, Strauss, \& Cardaciotto, 2007). Growth can be a painful process, understanding that PTG symptoms may need to get worse before a breakthrough emerges is closely aligned with developmental coaching which requires a crisis and unravelling of the self to open up the foundations for a perspective shift in order to move to a different level of reasoning and perception (Cavanagh, 2016). On this basis, PTG could potentially be seen as a new route to flourishing (Middleton, 2016). Indeed PTG like effects have been recorded following voluntary exposure to challenging experiences such as space travel (Suedfeld, Legkaia, \& Brcic, 2010) and arctic exploration (Kjærgaard, Leon, Venables, \& Fink, 2013).

\subsubsection{Working with PTS and pathways post trauma}

Trauma is idiosyncratic and manifests in many different ways (Bonanno \& Mancini, 2012). Awareness needs to be raised in the community that distress is a normal response following difficult events. Engaging in struggle does not necessarily result in a lifetime PTSD diagnosis. There are a number of different pathways, whether a return to baseline state pre-trauma, growth or psychosis (Seligman, 2018). 
A variety of therapeutic approaches could assist sufferers. Coaching for instance could play a key role in helping clients understand the heterogeneity of responses to life's difficulties, by focusing on the elements of PTS that can facilitate growth, while always looking out for signs of when referral is needed. PTG, like any other form of change, is a feedback cycle of resolving the discrepancies between the pre and post assumptive worldview, a cycle of reflection and learning about the self (Joseph, Murphy, et al., 2012). On this basis, the elements of deliberate rumination, reflection and rebuilding of assumptive worlds are all within the scope of coaching and other supportive approaches.

Working with trauma can also be potentially beneficial for therapists personally, providing inspiration or even opening up the possibility for positive effects resulting from vicarious PTG (Arnold, Calhoun, Tedeschi, \& Cann, 2005; Hall, 2015). Indeed, the Rapp-Ricciardi, Garcia et al., (2018) study has shown that PTG, in conjunction with positive affect and increased locus of control, actually raises a leader's receptivity to new knowledge and insights.

\subsection{Directions for Future Research}

This paper has sought to draw theoretical links between the outcomes of PTG studies with the practice of coaching and other therapeutic approaches to growth. There is little training for PTG in clinical practice, and virtually nothing supporting the development of potential expert companions.

An affective-cognitive model has been developed for the mental health professional founded on the principle that PTS as the generator of PTG (Joseph, Murphy, et al., 2012). The model takes the approach that PTS is a normal response to trauma and works with cognitions, appraisals, intrusions and emotional state and coping behaviours, the clinician works through the cycle of processing of the trauma until a reconciliation of pre and post assumptive worldview is completed (Joseph, Murphy, et al., 2012). This model has been specifically proposed for clinicians, however, with the evolution of coaching psychology, could be used as a basis, in conjunction with Joseph's (2011) THRIVE Model, for further research to develop an approach suitable for coaching and other growth-based approaches. Figure 1 (below) illustrates aspects of both of these models integrated with other PTG factors, demonstrating the potential relationship between both PTG and PTS through processes of accommodation and assimilation as potential pathways for intervention.

\subsubsection{Qualitative, interdisciplinary and transdisciplinary approaches to PTG}

Evidence of positive transformational change post trauma combined with the difficulty in defining its agreed predictors and proven interventions has prompted a range of interdisciplinary research (Birtles, 2018; Tedeschi et al., 2018). Seeking to understand the linkages and opportunities PTG presents within the broader therapeutic community and in particular the coaching environment should be included in such studies.

Almost all PTG research has been centred in mental health disciplines (Tedeschi et al., 2018), and a broader study of the construct into the humanities and coaching is called for. Given its nature, an interdisciplinary approach allows for the full nature of the construct and the multitude of approaches that can be adopted in working with it (Tedeschi et al., 2018). Of even more interest, is the emerging field of transdisciplinary research, fostering the creation of new approaches transcending disciplines to create a new holistic subdiscipline (Tedeschi et al., 2018).

This paper has sought to explore new ways of thinking and approaching PTG, looking at it through a different lens, to see what its elements can offer coaches and therapists in the context of struggle. While the struggles of the average coaching client may not meet an objective test of 
'trauma', subjectively the struggle may be sufficient to shatter core assumptions to spark the rebuilding growth process.

Figure 1: An affective-cognitive and THRIVE model view of the process of PTS and PTG
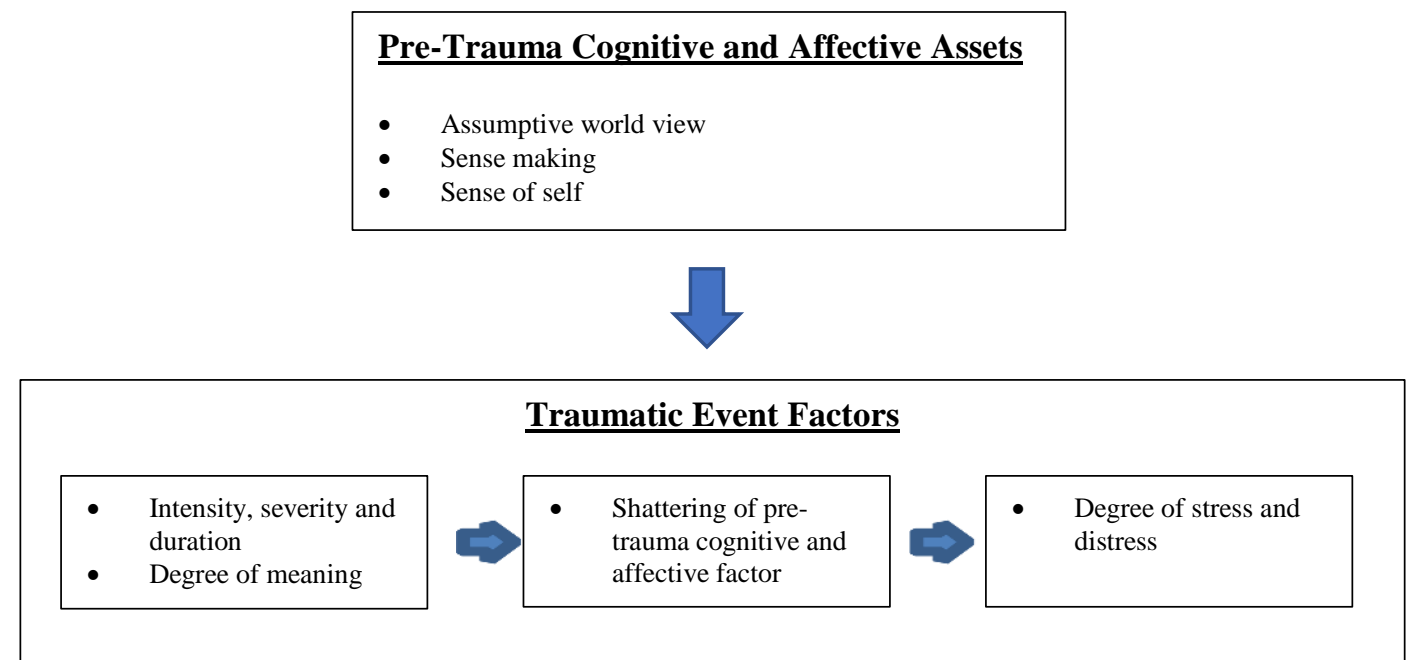

\section{$\checkmark$}

Potential Associated Factors of $\underline{\text { Assimilation }}$

- Intrusive / automatic ruminative thought

- $\quad$ Reliance on protective factors - Illusory growth

- $\quad$ Excess avoidance coping strategies (e.g., denial)
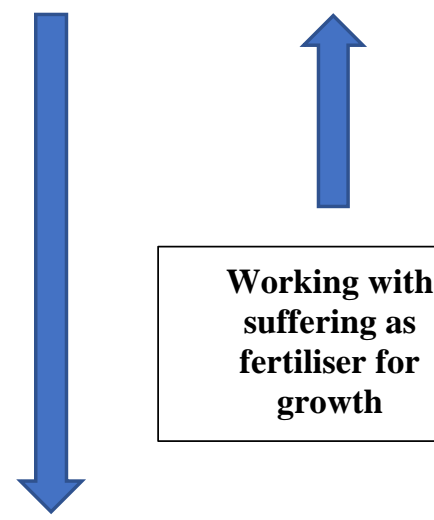
suffering as fertiliser for growth

\section{Potential Associated Factors of} $\underline{\text { Accommodation }}$

- Deliberate reflective rumination

- $\quad$ Professional social support

- Supported self-disclosure

- $\quad$ Early stage limited avoidance coping strategies

- $\quad$ Flexible approach based coping strategies

- Reappraisal of assumptions

- Narrative creation and reauthoring

- Positive change related action

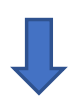

Potential increased

likelihood of

Distress or Post

Traumatic Stress

\section{Potential increased likelihood of Post Traumatic Growth}

Note. This figure summaries the factors identified in the literature review associated with a traumatic event experience that potentially impacts whether assimilation or accommodation occurs in reconciliation of pre and post assumptive world views. Aspects have been taken from both the THRIVE model (Joseph, 2011) and the affective-cognitive approach to intervention (Joseph, Murphy et al., 2012) to suggest relationships to both PTS and PTG.

Finally, as trauma and distress result in multiple pathways, research into the impact of naming conventions and links to development of a growth approach to trauma is warranted. Medical 
diagnosis of PTSD implies a final destination in disorder, embeds a fixed mindset and closes off opportunities for growth and different ways of looking at the pathways and outcomes of trauma.

The overreliance on the diagnosis of PTSD suggests that any exposure to a challenging event results in some form of post trauma stress condition. This contrasts with the evidence showing that only $8-12 \%$ of people exposed to profoundly traumatic experiences will in fact develop PTSD as defined in the Diagnostic and Statistical Manual of Mental Disorders (5th edition; DSM-5), of those most will recover within 6-12 months post trauma, and of the minority that continue to suffer, about half will respond to psychological treatment (Spence \& Joseph, 2017). Research into whether the medicalisation, naming conventions and terminology play a role in limiting or expanding a variety of pathways post trauma may prove beneficial in addressing this issue. If practitioners and researchers consider more carefully the range and type of impact that traumatic experiences can have on an individual, more opportunities may become available to support wellbeing recovery and growth for a broader range of effected populations.

\section{Conclusion}

Our evolving understanding of the complex nature of transformational growth post trauma presents a key opportunity for supporting personal development and wellbeing enhancement. While traditionally the domain of PTSD and medicalised interventions, the heterogeneity of responses post trauma mean that the fostering of these pathways will potentially fall into the scope of positive psychologists, coaches and other appropriately qualified expert companions. While often not in the realm of profound trauma, our lives regularly present challenges that, in the personal subjective context, can negatively impact our wellbeing, shatter our assumptions about ourselves and potentially that of those around us. Leveraging the learnings from PTG can strengthen and broaden approaches to fostering adult development and positive enhancement of individual wellbeing.

Learning to use life's challenges as a source of growth is the ultimate expression of the original aims of positive psychology, in seeking to bring out the potential in all of us, regardless of the circumstances of our lives.

\section{Authors}

Monica Sanki

The University of Sydney

Sean A. O'Connor

The University of Sydney

sean.oconnor@sydney.edu.au

\section{Publishing Timeline}

Received 23 September 2020

Revised version received 27 March 2021

Accepted 4 April 2021

Published 31 May 2021

\section{References}

Andysz, A., Najder, A., Merecz-Kot, D., \& Wojcik, A. (2015). Posttraumatic growth in women after breast cancer surgery-Preliminary results from a study of Polish patients. Health Psychology Report, 3(4), 336344. https://doi.org/10.5114/hpr.2015.52383 
Arnold, D., Calhoun, L. G., Tedeschi, R., \& Cann, A. (2005). Vicarious posttraumatic growth in psychotherapy. Journal of Humanistic Psychology, 45(2), 239-263. https://doi.org/10.1177/0022167805274729

Birtles, C. M. B. (2018). An interdisciplinary conceptualization of posttraumatic growth: A modified delphi study. Dissertation Abstracts International: Section B: The Sciences and Engineering, 78(10-B(E)), No Pagination Specified.

Bloom, S. L. (1998). By the crowd they have been broken, by the crowd they shall be healed: The social transformation of trauma. Posttraumatic growth: Positive changes in the aftermath of crisis, 179-213.

Boals, A., \& Schuler, K. L. (2018). Reducing reports of illusory posttraumatic growth: A revised version of the Stress-Related Growth Scale (SRGS-R). Psychological Trauma: Theory, Research, Practice, and Policy, 10(2), 190-198. https://doi.org/10.1037/tra0000267

Bonanno, G. A., \& Mancini, A. D. (2012). Beyond resilience and PTSD: Mapping the heterogeneity of responses to potential trauma. Psychological Trauma: Theory, Research, Practice, and Policy, 4(1), 74. https://doi.org/10.1037/a0017829

Calhoun, L., \& Tedeschi, R. (2006). The foundations of posttraumatic growth: An expanded framework. In L. G. Calhoun \& R. G. Tedeschi (Eds.), Handbook of posttraumatic growth: Research and practice (pp. 323). Mahwah, NJ: Erlbaum.

Calhoun, L. G., \& Tedeschi, R. G. (2013). Posttraumatic growth in clinical practice: Routledge New York. https://doi.org/10.4324/9780203629048

Cann, A., Calhoun, L. G., Tedeschi, R. G., Taku, K., Vishnevsky, T., Triplett, K. N., \& Danhauer, S. C. (2010). A short form of the Posttraumatic Growth Inventory. Anxiety, Stress \& Coping: An International Journal, 23(2), 127-137. https://doi.org/10.1080/10615800903094273

Cavanagh, M. J. (2016). The coaching engagement in the twenty-first century: New paradigms for complex times. Beyond Goals: Effective Strategies for Coaching and Mentoring, 151-184.

Copping, A., \& Shakespeare-Finch, J. E. (2013). Trauma and survival in African humanitarian entrants to Australia. In In K. M. Gow \& M. Celenski (Eds.) (Ed.), Mass trauma: Impact and recovery issues (pp. (pp. 331-348)). New York: Nova Science.

Drake, D. B. (2015). Narrative coaching: Bringing our new stories to life: CNC Press Petaluma, CA.

Epel, E. S., McEwen, B. S., \& Ickovics, J. R. (1998). Embodying Psychological Thriving: Physical Thriving in Response to Stress. Journal of social issues, 54(2), 301-322. https://doi.org/10.1111/j.15404560.1998.tb01220.x

Fontana, A., \& Rosenheck, R. (1998). Psychological benefits and liabilities of traumatic exposure in the war zone. Journal of Traumatic Stress: Official Publication of The International Society for Traumatic Stress Studies, 11(3), 485-503. https://doi.org/10.1023/A:1024452612412

Frankl, V. E. (1985). Man's search for meaning: Simon and Schuster.

Frazier, P., Conlon, A., \& Glaser, T. (2001). Positive and negative life changes following sexual assault. Journal of consulting and clinical psychology, 69(6), 1048. https://doi.org/10.1037/0022-006X.69.6.1048

Frazier, P., Tennen, H., Gavian, M., Park, C., Tomich, P., \& Tashiro, T. (2009). Does self-reported posttraumatic growth reflect genuine positive change? Psychological science, 20(7), 912-919. https://doi.org/10.1111/j.1467-9280.2009.02381.x

Garcia, F. E., Duque, A., \& Cova, F. (2017). The four faces of rumination to stressful events: A psychometric analysis. Psychological Trauma: Theory, Research, Practice, and Policy, 9(6), 758-765. https://doi.org/10.1037/tra0000289

Gorman, V. (2019, 10 June 2019). Carrying on after 'the world ends', Online. ABC News. Retrieved from https://www.msn.com/en-au/news/australia/carrying-on-after-the-world-ends/arAACCKpw?ocid=spartanntp

Hall, L. (2015). Coaching in Times of Crisis and Transformation: How to Help Individuals and Organisations Flourish: Kogan Page Publishers.

Hayes, A. M., Laurenceau, J.-P., Feldman, G., Strauss, J. L., \& Cardaciotto, L. (2007). Change is not always linear: The study of nonlinear and discontinuous patterns of change in psychotherapy. Clinical psychology review, 27(6), 715-723. https://doi.org/10.1016/j.cpr.2007.01.008 
Hefferon, K., Grealy, M., \& Mutrie, N. (2009). Post-traumatic growth and life threatening physical illness: A systematic review of the qualitative literature. British journal of health psychology, 14(2), 343-378. https://doi.org/10.1348/135910708X332936

Helgeson, V. S., Reynolds, K. A., \& Tomich, P. L. (2006). A Meta-Analytic Review of Benefit Finding and Growth. Journal of consulting and clinical psychology, 74(5), 797-816. https://doi.org/10.1037/0022006X.74.5.797

Hobfoll, S. E., Hall, B. J., Canetti-Nisim, D., Galea, S., Johnson, R. J., \& Palmieri, P. A. (2007). Refining our understanding of traumatic growth in the face of terrorism: Moving from meaning cognitions to doing what is meaningful. Applied Psychology, 56(3), 345-366. https://doi.org/10.1111/j.14640597.2007.00292.x

Hooper, L. M., Marotta, S. A., \& Depuy, V. (2009). A confirmatory factor analytic study of the Posttraumatic Growth Inventory among a sample of racially diverse college students. Journal of Mental Health, 18(4), 335-343. https://doi.org/10.1080/09638230802522502

Hooton, A. (2018). Leigh Sales: 'It just started to feel like nothing was safe'. Sydney Morning Herald, 29 September 2018. https://www.smh.com.au/lifestyle/life-and-relationships/leigh-sales-it-just-startedto-feel-like-nothing-was-safe-20180925-p505ta.html

Horswill, S. C., Desgagne, G., Parkerson, H. A., Carleton, R., \& Asmundson, G. J. (2016). A psychometric evaluation of hierarchical and oblique versions of five variants of the Posttraumatic Growth Inventory. Psychiatry Research, 246, 438-446. https://doi.org/10.1016/j.psychres.2016.10.027

Hughes, M. E., Alloy, L. B., \& Cogswell, A. (2008). Repetitive thought in psychopathology: The relation of rumination and worry to depression and anxiety symptoms. Journal of Cognitive Psychotherapy, 22(3), 271-288. https://doi.org/10.1891/0889-8391.22.3.271

Janoff-Bulman, R. (1992). Shattered assumptions: Towards a new psychology of trauma: New York: Free Press. Janoff-Bulman, R. (2004). Posttraumatic growth: Three explanatory models. Psychological inquiry, 15(1), 30-34.

Jayawickreme, E., \& Blackie, L. E. (2014). Post-traumatic growth as positive personality change: Evidence, controversies and future directions. European Journal of Personality, 28(4), 312-331. https://doi.org/10.1002/per.1963

Jin, Y., Xu, J., \& Liu, D. (2014). The relationship between post traumatic stress disorder and post traumatic growth: Gender differences in PTG and PTSD subgroups. Social Psychiatry and Psychiatric Epidemiology, 49(12), 1903-1910. https://doi.org/10.1007/s00127-014-0865-5

Jirek, S. L. (2017). Narrative reconstruction and post-traumatic growth among trauma survivors: The importance of narrative in social work research and practice. Qualitative Social Work: Research and Practice, 16(2), 166-188. https://doi.org/10.1177/1473325016656046

Joseph, S. (2011). What doesn't kill us: The new psychology of posttraumatic growth: Basic Books.

Joseph, S. (2012). What doesn't kill us. The Psychologist, 25(11), 816-819.

Joseph, S., \& Linley, P. (2004). Adversarial growth and positive change following trauma: Theory, research, and practice. Ricerche di Psicologia, 27(1), 177-190.

Joseph, S., \& Linley, P. (2005). Positive Adjustment to Threatening Events: An Organismic Valuing Theory of Growth Through Adversity. Review of General Psychology, 9(3), 262-280. https://doi.org/10.1037/1089-2680.9.3.262

Joseph, S., Maltby, J., Wood, A. M., Stockton, H., Hunt, N., \& Regel, S. (2012). The Psychological WellBeing-Post-Traumatic Changes Questionnaire (PWB-PTCQ): Reliability and validity. Psychological Trauma: Theory, Research, Practice, and Policy, 4(4), 420-428. https://doi.org/10.1037/a0024740

Joseph, S., Murphy, D., \& Regel, S. (2012). An affective-cognitive processing model of post-traumatic growth. Clinical Psychology \& Psychotherapy, 19(4), 316-325. https://doi.org/10.1002/cpp.1798

Kampman, H., Hefferon, K., Wilson, M., \& Beale, J. (2015). "I can do things now that people thought were impossible, actually, things that I thought were impossible": A meta-synthesis of the qualitative findings on posttraumatic growth and severe physical injury. Canadian Psychology/psychologie canadienne, 56(3), 283. https://doi.org/10.1037/cap0000031 
Kilmer, R. P., Gil-Rivas, V., Tedeschi, R. G., Cann, A., Calhoun, L. G., Buchanan, T., \& Taku, K. (2009). Use of the revised Posttraumatic Growth Inventory for Children. Journal of Traumatic Stress, 22(3), 248-253. https://doi.org/10.1002/jts.20410

Kjærgaard, A., Leon, G. R., Venables, N. C., \& Fink, B. A. (2013). Personality, personal values and growth in military special unit patrol teams operating in a polar environment. Military Psychology, 25(1), 1322. https://doi.org/10.1037/h0094753

Kuhn, E., Greene, C., Hoffman, J., Nguyen, T., Wald, L., Schmidt, J., . . Ruzek, J. (2014). Preliminary evaluation of PTSD Coach, a smartphone app for post-traumatic stress symptoms. Military medicine, 179(1), 12-18. https://doi.org/10.7205/MILMED-D-13-00271

Kunz, S., Joseph, S., Geyh, S., \& Peter, C. (2018). Coping and posttraumatic growth: A longitudinal comparison of two alternative views. Rehabilitation Psychology, 63(2), 240-249. https://doi.org/10.1037/rep0000205

la Cour, P., Nielsen, A. B. S., Andersen, S. B., \& Madsen, T. (2016). The Psychological Well-Being-PostTraumatic Changes Questionnaire: Validation of the Danish version. Traumatology, 22(4), 271-277. https://doi.org/10.1037/trm0000080

Lamela, D., Figueiredo, B., Bastos, A., \& Martins, H. (2014). Psychometric properties of the Portuguese version of the Posttraumatic Growth Inventory Short Form among divorced adults. European Journal of Psychological Assessment, 30(1), 3-14. https://doi.org/10.1027/1015-5759/a000161

Lechner, S. C., Zakowski, S. G., Antoni, M. H., Greenhawt, M., Block, K., \& Block, P. (2003). Do sociodemographic and disease-related variables influence benefit-finding in cancer patients? PsychoOncology: Journal of the Psychological, Social and Behavioral Dimensions of Cancer, 12(5), 491-499. https://doi.org/10.1002/pon.671

Linley, P., \& Joseph, S. (2004). Positive Change Following Trauma and Adversity: A Review. Journal of Traumatic Stress, 17(1), 11-21. https:/doi.org/10.1023/B:JOTS.0000014671.27856.7e

Linley, P., \& Joseph, S. (2005). The Human Capacity for Growth Through Adversity. American psychologist, 60(3), 262-264. https://doi.org/10.1037/0003-066X.60.3.262b

Mack, J., Herrberg, M., Hetzel, A., Wallesch, C. W., Bengel, J., Schulz, M., . . Schonberger, M. (2015). The factorial and discriminant validity of the German version of the Post-traumatic Growth Inventory in stroke patients. Neuropsychological Rehabilitation, 25(2), 216-232. https://doi.org/10.1080/09602011.2014.918885

Maercker, A., \& Herrle, J. (2003). Long-term effects of the Dresden bombing: Relationships to control beliefs, religious belief, and personal growth. Journal of Traumatic Stress, 16(6), 579-587. https://doi.org/10.1023/B:JOTS.0000004083.41502.2d

Maercker, A., \& Zoellner, T. (2004). The Janus face of self-perceived growth: Toward a two-component model of posttraumatic growth. Psychological inquiry, 15(1), 41-48.

McFarland, C., \& Alvaro, C. (2000). The impact of motivation on temporal comparisons: Coping with traumatic events by perceiving personal growth. Journal of personality and social psychology, 79(3), 327. https://doi.org/10.1037/0022-3514.79.3.327

Middleton, H. (2016). Flourishing and posttraumatic growth. An empirical take on ancient wisdoms. Health Care Analysis, 24(2), 133-147. https://doi.org/10.1007/s10728-016-0318-2

Morris, B. A., Shakespeare-Finch, J., Rieck, M., \& Newbery, J. (2005). Multidimensional nature of posttraumatic growth in an Australian population. Journal of Traumatic Stress: Official Publication of The International Society for Traumatic Stress Studies, 18(5), 575-585. https://doi.org/10.1002/jts.20067

Morris, B. A., Wilson, B., \& Chambers, S. K. (2013). Newfound compassion after prostate cancer: a psychometric evaluation of additional items in the Posttraumatic Growth Inventory. Supportive Care in Cancer, 21(12), 3371-3378. https://doi.org/10.1007/s00520-013-1903-7

Nolen-Hoeksema, S., \& Davis, C. G. (2004). Theoretical and methodological issues in the assessment and interpretation of posttraumatic growth. Psychological inquiry, 15(1), 60-64.

Nolen-Hoeksema, S., Wisco, B. E., \& Lyubomirsky, S. (2008). Rethinking rumination. Perspectives on Psychological Science, 3(5), 400-424. https://doi.org/10.1111/j.1745-6924.2008.00088.x

Norcross, J. C., \& Wampold, B. E. (2011). What works for whom: Tailoring psychotherapy to the person. Journal of Clinical Psychology, 67(2), 127-132. https://doi.org/10.1002/jclp.20764 
Norris, F. (1996). Designing trauma studies: Basic principles. Trauma research methodology, 22-55.

Palmer, G. A., Graca, J. J., \& Occhietti, K. E. (2012). Confirmatory factor analysis of the Posttraumatic Growth Inventory in a veteran sample with posttraumatic stress disorder. Journal of Loss and Trauma, 17(6), 545-556. https://doi.org/10.1080/15325024.2012.678779

Peterson, C., Maier, S. F., \& Seligman, M. E. (1993). Learned helplessness: A theory for the age of personal control. Oxford University Press

Peterson, C., Park, N., Pole, N., D'Andrea, W., \& Seligman, M. E. (2008). Strengths of Character and Posttraumatic Growth. Journal of Traumatic Stress, 21(2), 214-217. https://doi.org/10.1002/jts.20332

Prati, G., \& Pietrantoni, L. (2009). Optimism, social support, and coping strategies as factors contributing to posttraumatic growth: A meta-analysis. Journal of Loss and Trauma, 14(5), 364-388. https://doi.org/10.1080/15325020902724271

Rapp-Ricciardi, M., Garcia, D., \& Archer, T. (2018). Personal attributes linked to empowerment that influence receptivity to coaching leadership. Coaching: An International Journal of Theory, Research and Practice, 11(1), 30-45. https://doi.org/10.1080/17521882.2017.1330352

Rogers, C. R. (1951). Client-centered counseling. In: Boston: Houghton-Mifflin.

Rossouw, P. (2013). The neuroscience of talking therapies. Paper presented at the Keynote lecture - National Conference of the College of Counselling Psychologists, Melbourne VIC Australia.

Ryan, R. M., \& Deci, E. L. (2000). Self-determination theory and the facilitation of intrinsic motivation, social development, and well-being. American psychologist, 55(1), 68. https://doi.org/10.1037/0003066X.55.1.68

Ryff, C. D., \& Singer, B. (1998). The contours of positive human health. Psychological inquiry, 9(1), 1-28. https://doi.org/10.1207/s15327965pli0901_1

Ryff, C. D., \& Singer, B. H. (2008). Know thyself and become what you are: A eudaimonic approach to psychological well-being. Journal of Happiness Studies, 9(1), 13-39. https://doi.org/10.1007/s10902-0069019-0

Seligman, M. (2018). HBR's 10 must reads on mental toughness: with bonus interview of Martin E.P. Seligman. Boston, Massachusetts.

Seligman, M. E. P. (2000). Positive psychology: An introduction. American psychologist, 55(1), 5-14. https://doi.org/10.1037/0003-066X.55.1.5

Shakespeare-Finch, J., \& Lurie-Beck, J. (2014). A meta-analytic clarification of the relationship between posttraumatic growth and symptoms of posttraumatic distress disorder. Journal of anxiety disorders, 28(2), 223-229. https://doi.org/10.1016/j.janxdis.2013.10.005

Shakespeare-Finch, J., Schweitzer, R. D., King, J., \& Brough, M. (2014). Distress, coping, and posttraumatic growth in refugees from Burma. Journal of Immigrant E Refugee Studies, 12(3), 311-330. https://doi.org/10.1080/15562948.2013.844876

Sheldon, K. M., \& King, L. (2001). Why positive psychology is necessary. American psychologist, $56(3), 216$. https://doi.org/10.1037/0003-066X.56.3.216

Spence, G., \& Joseph, S. (2017). Coaching for post-traumatic growth: An appropriate response to the devastations of life? In The SAGE handbook of coaching (pp. 399-418). Thousand Oaks, CA: Sage Publications, Inc; US.

Splevins, K., Cohen, K., Bowley, J., \& Joseph, S. (2010). Theories of posttraumatic growth: Cross-cultural perspectives. Journal of Loss and Trauma, 15(3), 259-277. https://doi.org/10.1080/15325020903382111

Steger, M. F., Frazier, P. A., \& Zacchanini, J. L. (2008). Terrorism in two cultures: Stress and growth following September 11 and the Madrid train bombings. Journal of Loss and Trauma, 13(6), 511-527. https://doi.org/10.1080/15325020802173660

Suedfeld, P., Legkaia, K., \& Brcic, J. (2010). Changes in the hierarchy of value references associated with flying in space. Journal of personality, 78(5), 1411-1436. https://doi.org/10.1111/j.1467-6494.2010.00656.x

Sumalla, E. C., Ochoa, C., \& Blanco, I. (2009). Posttraumatic growth in cancer: Reality or illusion? 话. Clinical psychology review, 29, 24-33. https://doi.org/10.1016/j.cpr.2008.09.006

Taku, K., \& Cann, A. (2014). Cross-national and religious relationships with posttraumatic growth: The role of individual differences and perceptions of the triggering event. Journal of Cross-Cultural Psychology, 45(4), 601-617. https://doi.org/10.1177/0022022113520074 
Tanner, A., Voon, D., Hasking, P., \& Martin, G. (2013). Underlying structure of ruminative thinking: Factor analysis of the Ruminative Thought Style Questionnaire. Cognitive therapy and research, 37(3), 633-646. https://doi.org/10.1007/s10608-012-9492-1

Taylor, S. E., Kemeny, M. E., Reed, G. M., Bower, J. E., \& Gruenewald, T. L. (2000). Psychological resources, positive illusions, and health. American psychologist, 55(1), 99. https://doi.org/10.1037/0003066X.55.1.99

Tedeschi, R., \& Blevins, C. (2017). Posttraumatic growth: a pathway to resilience. The Routledge international handbook of psychosocial resilience, 324-333.

Tedeschi, R. G., \& Calhoun, L. G. (1995a). Trauma \& transformation: Growing in the aftermath of suffering. https://doi.org/10.4135/9781483326931

Tedeschi, R. G., \& Calhoun, L. G. (1995b). Trauma and transformation: Sage.

Tedeschi, R. G., \& Calhoun, L. G. (1996). The Posttraumatic Growth Inventory: Measuring the positive legacy of trauma. Journal of Traumatic Stress, 9(3), 455-472. https://doi.org/10.1002/jts.2490090305

Tedeschi, R. G., \& Calhoun, L. G. (2004). " Posttraumatic growth: Conceptual foundations and empirical evidence". Psychological inquiry, 15(1), 1-18. https://doi.org/10.1207/s15327965pli1501_01

Tedeschi, R. G., Shakespeare-Finch, J., Taku, K., \& Calhoun, L. G. (2018). Posttraumatic growth: theory, research, and applications: Routledge. https://doi.org/10.4324/9781315527451

Treynor, W., Gonzalez, R., \& Nolen-Hoeksema, S. (2003). Rumination reconsidered: A psychometric analysis. Cognitive therapy and research, 27(3), 247-259. https://doi.org/10.1023/A:1023910315561

Van der Kolk, B. A. (2015). The body keeps the score: Brain, mind, and body in the healing of trauma: Penguin Books.

Waters, L., \& Strauss, G. (2016). Posttraumatic growth during unemployment: A qualitative examination of distress and positive transformation. International Journal of Wellbeing, 6(1), 117-141. https://doi.org/10.5502/ijw.v6i1.441

Weiss, T. E., \& Berger, R. E. (Eds.) (2010). Posttraumatic growth and culturally competent practice: Lessons learned from around the globe. John Wiley \& Sons. https://doi.org/10.1002/9781118270028

Westphal, M., \& Bonanno, G. A. (2007). Posttraumatic growth and resilience to trauma: Different sides of the same coin or different coins? Applied Psychology, 56(3), 417-427. https://doi.org/10.1111/j.14640597.2007.00298.x

Yoshida, H., Kobayashi, N., Honda, N., Matsuoka, H., Yamaguchi, T., Homma, H., \& Tomita, H. (2016). Post-traumatic growth of children affected by the Great East Japan Earthquake and their attitudes to memorial services and media coverage. Psychiatry and Clinical Neurosciences, 70(5), 193-201. https://doi.org/10.1111/pcn.12379

Zheng, P., \& Gray, M. J. (2015). Posttraumatic coping and distress: An evaluation of Western conceptualization of trauma and its applicability to Chinese culture. Journal of Cross-Cultural Psychology, 46(5), 723-736. https://doi.org/10.1177/0022022115580848

Zoellner, T., Rabe, S., Karl, A., \& Maercker, A. (2008). Posttraumatic growth in accident survivors: Openness and optimism as predictors of its constructive or illusory sides. Journal of Clinical Psychology, 64(3), 245-263. https://doi.org/10.1002/jclp.20441 